\title{
Charting Disaster Recovery via Google Street View: A Social Science Perspective on Challenges Raised by the Fukushima Nuclear Disaster
}

\author{
Leslie Mabon ${ }^{1}$
}

Published online: 22 June 2016

(C) The Author(s) 2016. This article is published with open access at Springerlink.com

\begin{abstract}
There is increasing interest in using Google Street View (GSV) for research purposes, particularly with regard to "virtually auditing" the built environment to assess environmental quality. Research in this field to date generally suggests GSV is a reliable means of understanding the "real world" environment. But limitations around the dates and resolution of images have been identified. An emerging strand within this literature is also concerned with the potential of GSV to understand recovery post-disaster. Using the GSV data set for the evacuated area around the Fukushima Dai'ichi nuclear power plant as a case study, this article evaluates GSV as a means of assessing disaster recovery in a dynamic situation with remaining uncertainty and a significant value and emotive dimension. The article suggests that GSV does have value in giving a high-level overview of the postdisaster situation and has potential to track recovery and resettlement over time. Drawing on social science literature relating to Fukushima, and disasters more widely, the article also argues it is imperative for researchers using GSV to reflect carefully on the wider socio-cultural contexts that are often not represented in the photo montage.
\end{abstract}

Keywords Digital representation of place - Fukushima nuclear disaster - Google Street View · Post-disaster recovery $\cdot$ Social dimensions of energy

Leslie Mabon

1.j.mabon@rgu.ac.uk

1 School of Applied Social Studies, Robert Gordon University, Aberdeen, Scotland AB10 7QG, UK

\section{Introduction}

The March 2011 accident at the Fukushima Dai'ichi nuclear power plant (FDNPP), triggered by the Great East Japan Earthquake and Tsunami, led to large-scale releases of radiation over the land and sea of Fukushima Prefecture. The resulting contamination caused the evacuation of more than 100,000 people, and continues to have effects on the region's produce and environments. Although the causes and immediate effects of the Fukushima disaster are certainly unique, the longer-term recovery issues may share similarity to other natural and human-induced disasters (for example, the effects of climate change) in that they are characterized by significant uncertainty, have profound effects on where and how citizens can live their lives, and could potentially even be irreversible. Tracking recovery under such ecological and societal complexity may thus yield useful lessons for the management and mitigation of future disasters.

Systematic and repeated auditing of environments for comprehensive disaster recovery monitoring has implications in terms of cost, staff time, and potential exposure to risk. There is therefore an emerging interest in the role that Google Street View (GSV) can play in remote assessment of recovery from disastrous events (Curtis et al. 2013) in a less logistical- and cost-intensive way. This study evaluates the possibility of using GSV to track recovery from a disaster such as Fukushima where the risk to humans may not be immediately visible, where there is significant subjectivity around what constitutes adequate recovery, and where citizens' and decision makers' values and perceptions heavily influence how the issue is viewed. After providing contextual background to the Fukushima disaster and to GSV in northeast Japan, the article reviews existing literature on the application of GSV for environmental 
auditing and also raises social science concerns around digital representations of place. It then outlines the deskbased methodology for the study before assessing-with reference to examples from GSV Fukushima-the merits and limitations of the data set for charting post-disaster recovery. It argues in particular that whilst GSV is indeed a useful tool for disaster scholars, when making judgments as to the "recovery" or otherwise of an area it is imperative to temper conclusions drawn from GSV imagery with wider contextual understanding, especially in terms of the sociopolitical dimensions of the disaster.

\section{Background and Context}

This section provides contextual information to aid the reader in understanding the topic matter of the articlenamely, how the land around the FDNPP is represented in GSV. The overview is broken into two parts. The first deals with the effects of the FDNPP disaster on land, and how the status of contaminated land has evolved since March 2011. The second gives a summary of the various initiatives undertaken through Google's mapping products in and around Fukushima Prefecture since the March 2011 disaster.

\subsection{The Fukushima Nuclear Disaster and its Effects on Land}

On the afternoon of 11 March 2011, a magnitude 9.0 earthquake off the northeastern coast of Japan triggered a large tsunami that reached up to $40 \mathrm{~m}$ in height and stretched as far as $10 \mathrm{~km}$ inland. The combined effects of this earthquake and tsunami resulted in over 15,000 deaths and left more than 2000 people missing (for a fuller overview see National Geophysical Data Center 2015). One of the most well-documented consequences was the incident at the Fukushima Dai' ichi nuclear power plant, located on the coast of Fukushima Prefecture. Cooling systems for the plant's nuclear reactors and spent fuel pools were taken offline by the earthquake and tsunami, leading to hydrogen explosions and significant releases of radiation into the surrounding environment in the days following the earthquake (Wakeford 2011).

Evacuation orders started to be issued shortly after the tsunami, and, following the first hydrogen explosion on 12 March 2011, an evacuation order was imposed on all residents living within $20 \mathrm{~km}$ of the plant. Some areas beyond this $20 \mathrm{~km}$ radius were also subsequently evacuated (mainly to the northwest) due to high deposition levels. In total approximately 154,000 people evacuated, around 109,000 of them from areas where evacuation orders were imposed (Reconstruction Agency 2015). In August 2013 the $20 \mathrm{~km}$ restricted area and additional evacuated areas beyond were consolidated into a "Special Decontamination Area" and divided into three categories based on anticipated exposure to air dose radiation in microSieverts per year (hereafter $\mathrm{mSv} / \mathrm{year}$ ) expected in each location: areas where evacuation orders are ready to be lifted (less than $20 \mathrm{mSv} /$ year); areas where residents are allowed to return for brief visits but not yet permitted to live $(20-50 \mathrm{mSv} /$ year); and areas over $50 \mathrm{mSv} /$ year where it is expected that the residents will have difficulties in returning for a long time (Ministry of Environment 2015). Remediation work is underway within the Special Decontamination Area with the target of reducing annual exposure to lower than $20 \mathrm{mSv} /$ year over the next several years, and the process of securing temporary and permanent sites for storing waste generated by remediation is ongoing (Ministry of Environment 2015). The lifting of evacuation orders has commenced in some towns (for example, Kawauchi to the southwest and Naraha to the south of FDNPP). But as is discussed in Sect. 5.2, citizen return has been limited due to concerns over radioactivity and limited availability of key infrastructure.

\subsection{GSV and Northeast Japan}

Since late 2011, Google has augmented its satellite map database with GSV coverage of northeast Japan, commencing in December 2011 with many of the affected coastal and inland areas (Kawai 2011). Simultaneously, the "Memories for the Future"/Miraikioku project was launched, whereby users can compare "before" and "after" GSV imagery of some affected areas, albeit largely further north in Miyagi and Iwate Prefectures in areas hit hardest by the tsunami. It is even possible for people to upload their own photos and videos from before and after the disasters (Google n.d.). In late 2012, the interiors of some buildings damaged by the earthquake and tsunami (and in many cases scheduled for demolition) were photographed and added to the GSV portfolio (Kawai 2012). In spring 2013, in collaboration with civic authorities, Google added coverage of Namie-machi, a settlement inside the nuclear exclusion zone that remains off-limits to residents (Google and Baba 2013). GSV imagery of much more of the evacuated area was added over the following months, and imagery for most of Tohoku (including areas mapped shortly after the disaster) was updated around that time. In mid-2014 imagery of the Tohoku coastline as visible from the sea was added to GSV, the images having been taken in collaboration with local fishers (Asahi Shinbun 2014). Sections of imagery within the "exclusion zone" continue to be periodically updated, and although no information is given as to when or why such updates take place, it is possible to switch between older and newer photographs 
when more than one image for a place exists (Google 2014).

Much of Google's work in northeast Japan has been carried out with the apparent aim of preserving memory of the events of March 2011 (Asahi Shimbun 2014). Another stated aim of adding photography of areas inside the exclusion zone was to help viewers in the wider world "understand the current state of Namie-machi and the tremendous gravity of the situation" (Google and Baba 2013). To get a sense of the extent to which GSV might not only bring viewers towards this goal of "understanding" Fukushima, but also can be a potentially useful scholarly tool for understanding post-disaster recovery, the article next reviews existing work on the role and issues embedded in digital mapping that define the nature of GSV.

\section{3 “Auditing” Environments Through GSV}

Less et al. (2015) believe there is a need to evaluate the reliability and feasibility of new web-based geographic imaging tools like GSV to better understand their value for social science research. There is already a body of scholarly literature exploring what can be learned or understood about "real world" places from their GSV counterparts, as summarized by Vandeviver (2014). Much of this research is concerned with environmental health, "virtually auditing" the built environment to identify options for healthier physical activity and transport choices (Rundle et al. 2011; Odgers et al. 2012; Kelly et al. 2013). However the scholarly use of GSV has also included assessment of species distribution (Rousselet et al. 2013) and crime studies (Vandeviver 2014). Environmental health studies generally consider GSV a good proxy for the "real" environment. Badland et al. (2010, p. 1008) suggest that GSV allows viewers to look at the landscape "as if in reality" and van Wolleghem et al. (2014, p. 7) conclude that "virtual auditing" via GSV offers "an objective method" with which to draw conclusions about the built environment. Suggested limitations to the value of GSV include sudden changes in the dates at which adjacent images are taken, and restrictions to what can be seen imposed by the resolution or viewpoint of imagery (Rousselet et al. 2013; Less et al. 2015).

There is additional emerging interest in the utility of photo- or video-based street-level video surveys such as GSV as a means of charting post-disaster recovery. Curtis et al. (2007) believe street-level video auditing helps to understand the spatial dimensions of post-disaster stress in a way that allows vulnerable populations to be targeted and resilience to be developed. GSV too can accomplish this goal by tracking recovery over time and giving citizens information to allow them to decide if or when to return.
Based on research of this nature carried out in the United States that explores recovery from tornadoes, hurricanes, and wildfires (Curtis and Mills 2012; Curtis et al. 2013), Curtis et al. (2013) suggest GSV has potential as a means of remotely tracking post-disaster recovery, but users should exercise caution and pay careful attention to the "spatiotemporal instability" (changes in image dates) that may introduce errors into tracking recovery. Curtis et al. (2015) add that reliance on GSV restricts the researcher to the available imagery and discourages collection and integration of independent, field-based data.

There is thus precedent and cautious support for the use of GSV to understand disaster recovery from afar, especially given the significant potential risks and access limitations that exist in disaster areas like Fukushima, which this article evaluates further. Using repeat photography to assess change in the environment over time is, however, not new. In a seminal study, Hastings and Turner (1965) use comparative photography to show vegetation change over time in the southwest United States due to human and environmental factors. Bahre (1991) cautions that these repeat photography techniques can overlook historical factors that may have contributed to the changes. Further, from a social rather than environmental science perspective, Pink (2012) suggests that using visual approaches to understand "places" online is a development of-but not removed from - the ideas that have long informed how place is researched in the "real world." Although GSV certainly opens up new scholarly possibilities, caution must therefore be exercised not to over-state the novelty of remotely researching environments through photographs.

It is also important to reflect on the sociopolitical dimensions of online visualization tools. Kasperson et al. (2001) warn of the influence large organizations have on the context and terms of contemporary societal debates on risk. With Exeter et al. (2014) reminding us that GSV is ultimately a commercial product, somewhat missing from much of this GSV-specific research is consideration of how sociopolitical forces may influence what we can and cannot see. For instance, Zook and Graham (2007) argue the ranking algorithms and mechanisms used to order search results in Google Maps more widely may not be as "objective" as one might be led to believe; these ranking techniques may reflect underlying economic, social, and cultural imperatives that are not outwardly visible on the map. Perkins (2014) notes that underneath a desire for objectivity digital maps are a result of the people and procedures that produce them, with the digital map being volatile and subject to update and change over time. Referring specifically to GSV, Power et al. (2013) hold that decisions on which places are photographed for inclusion in the data set (and which are not) may be politically or ideologically motivated by preexisting perceptions of 
specific places. Viewing the Fukushima landscape must thus be tempered with critical reflection on the processes that may influence what the "objective" GSV camera shows the viewer.

This article builds on previous research by evaluating: (1) the immediate value of GSV for understanding recovery in a situation where the key risk (radiation) is invisible and the disaster is arguably continuing through ongoing radioactive leakage and contamination; and (2) the ability of GSV to engage with some of the contestations around what constitutes a "safe" and "liveable" environment in a highly values-driven context such as the Fukushima disaster.

\section{A Note on Methodology}

This study involved desk-based empirical research into Google's Street View coverage of land around Fukushima Dai'ichi. It draws on two key sources of data-primarily the actual GSV imagery itself, but also extant physical and social science research into Fukushima contamination that provides additional information on the landscapes being viewed. This "background map" of both actual information on radioactive contamination and also the sociopolitical debates around Fukushima radiation was considered important for allowing proper assessment of the issues presented and excluded from Fukushima GSV. Relevant references and debates are cited where appropriate to illustrate aspects of the GSV landscape.

For flexibility to identify emerging themes in the data, a qualitative approach was selected based on Rose's (2001) explanation of visual methods and Pink's (2012) idea of visual online ethnography as a means of understanding how "places" are created online. The latter of these is especially pertinent given this article's interest in how GSV represents post-disaster space. The concern with aspects of disaster recovery that may not be visible in the GSV landscape fits well with Pink's advocacy for considering how what is presented online relates to wider processes and understandings that happen away from the Internet. In sum, a qualitative ethnographic approach allowed the researcher to build deep understanding of the towns and villages around FDNPP by exploring the map freely, and also drawing in contextual material from outside of GSV. Nonetheless, to avoid being drawn only to places where one may expect to find "exciting" or "extreme" scenes, a semistructured strategy was taken to viewing the Fukushima landscape on GSV. Using the maps of different levels of contamination produced by the Japanese Government's Reconstruction Agency, landscapes were sampled corresponding to areas designated as being under $20 \mathrm{mSv} / \mathrm{yr}$, those with anticipated exposure in the range of $20-50 \mathrm{mSv} /$ year, and those with anticipated exposure over $50 \mathrm{mSv} /$ year. Attention was also paid to places that had been subject to existing social science studies-such as Iitate (Gill 2013), Minami Soma (McNeill and Quintana 2013), and Tomioka (Sato 2014) - to get a fuller sense of how underlying social issues may or may not come across in the GSV photomontage. A "control" area in the west of Fukushima, away from evacuation orders or radiation projections, was also selected to encompass both a rural (Kitakata Town) and urban (Aizuwakamatsu City) setting and give a sense of what a less nuclear Fukushima landscape may look like.

No set pattern for navigation was followed while moving through the virtual landscape afforded by GSV, but care was taken to examine a range of environments within each sampling area-coastal, inland, built-up, countryside. Themes in the landscape were recorded in the form of descriptive notes throughout the navigation process and, adapting the Parkhill et al. (2014) approach to qualitatively understanding energy and landscapes, developed iteratively based on relationship to ideas and themes identified in the underlying literature on Fukushima radiation.

GSV itself is not static. Images of Fukushima contained within it - and thus the precise nature of the viewable landscape-are likely to be updated over time. During the gestation of this article previously viewable sections became temporarily inaccessible but later reappeared, and photographs in some other areas were refreshed with newer images (the older images still being accessible by selecting the "Digital Timeline" option to view previous photo sets). For this reason this article concerns itself more generally with the limitations of GSV as a system to encapsulate the indeterminacies and complexities of a disaster. Specific examples are given to illustrate wider trends in the landscape, but are not intended to stand as the "only" examples of given phenomena.

\section{Post-Disaster Fukushima in GSV}

This section assesses the value of GSV as a means of understanding post-disaster recovery. The ability of GSV to make visible radiation risks, its potential to track recovery over time, and the challenges for incorporating the socio-political context underpinning the Fukushima disaster are evaluated in turn. Although the case study, and hence the focus, is on the Fukushima nuclear accident, more general observations are drawn about opportunities or limitations when using GSV as a research tool in a disaster context. Where reference is made to specific locations or phenomena found in GSV, coordinates (and the date of image to which the reader's attention is drawn) are provided in footnotes to allow independent verification. 
However, as above it should be noted that images may be removed over time and/or supplemented with newer photography.

\subsection{How well can GSV be Used to Assess Potential Risks to Humans?}

It is important at the outset to be clear about whether the area around the FDNPP ought to be considered a landscape of risk to humans. Radioactivity has the potential to rupture the integrity of all that comes into contact with it (Gregson 2012) and in sufficient doses or quantities is lethally dangerous (Nakamura and Kikuchi 2011). Because cesium nuclides corresponding to the accident have been detected at every location surveyed after the Fukushima accident (Saito et al. 2015), by definition the area can be considered a landscape of risk that has been "exposed to radioactive contamination" (Blowers 1999, p. 241).

Much of the literature on the value of GSV for auditing environments necessarily emphasizes visual characteristics such as the decay of the built environment (Odgers et al. 2012), roadside signage (Less et al. 2015), or large species (Rousselet et al. 2013) by virtue of the nature and limitations of GSV. This clearly has potential to be problematic for using GSV to assess a post-nuclear accident landscape, since radiation is invisible (Pezullo and Depoe 2010) and requires access to specialist technologies to make its presence "visible" (Gregson 2012). A key question to address is thus how effective visual "proxies" for radioactive contamination may be within GSV as a means of understanding the nature of contamination.

In one respect GSV in Fukushima does give a broad overview of the sheer scale of the challenges at hand, and the different gradients of contamination across space. A viewer can approximate the presence and heterogeneity of environmental radioactivity by viewing the physical infrastructure that measures and classifies contaminationgates and barriers preventing access to blocks, parts of towns or even whole villages deemed too radioactive for occupancy; radiation meters at the side of roads; signage explaining that an area is one where return will be difficult for a long time. The extent to which buildings have been repaired and people returned (for example, the presence of traffic on roads and/or pedestrians at the roadside) may also correlate with levels of contamination. In the most contaminated areas, for example the towns of Okuma ${ }^{1}$ and Namie, ${ }^{2}$ buildings can still be seen collapsed or damaged by the 2011 earthquake and tsunami. Further away from FDNPP, areas "released" from evacuation tend to have more intact buildings, more road traffic and pedestrians,

\footnotetext{
1 37.4077222, 141.032107 (September 2015).

2 37.4911027, 140.9938416 (September 2015).
}

and less overgrown vegetation. As discussed further in Sects. 5.2 and 5.3, there is also evidence of decontamination activities spread out across different mapped sites. This is indicated by the removal of contaminated topsoil and debris for storage, and illustrated by black or white sacks filled with soil gathered at roadsides ${ }^{3}$ as well as by piles of household waste awaiting uplift. ${ }^{4}$ GSV may thus be a useful means of visualizing the scale and extent of decontamination and remediation work required in Fukushima, and allows researchers to understand remotely the magnitude of irradiation issues and thus critically engage with "official" time frames for decontamination.

Missing from the photographic landscape, if not actively suppressed or discouraged, is any sort of actual information on the levels of environmental radioactivity and its effects on health via different pathways. The user interface does not give any explanation as to the level of ambient radioactivity or the categorization of the landscape one is viewing. Unless the user independently matches up the GSV data set with maps of radioactive deposition or current background radioactivity readings, ${ }^{5}$ there is little direct indication of the relative levels of contamination. Providing such information could give rise to an entirely separate issue over whose data was being provided and the extent to which it could be seen to be representative and accurate (McNeill and Quintana 2013; Gill 2013; Morris-Suzuki 2014). Other sources give anecdotal accounts of citizens measuring higher radiation levels than "official" government meters, or call into question whether the levels recorded are perceived by residents and workers as "safe" or not (Fukushima Minpo 2012). Yet in any case there is at base little to give the viewer a direct sense of how much radiation one might expect to be exposed to in the "real life" version of the landscape being viewed, or how this may vary across space.

In the absence of any realistic guidance on the level of "invisible" radioactive contamination, the virtual viewer may be forced to rely on visual cues in the environment as proxies for high radioactivity. Spatiotemporal instability (Curtis et al. 2013) in the Fukushima GSV dataset makes this problematic, however. Signs and barriers at the entrances to highly contaminated areas may suddenly (re)appear or disappear as one transitions without warning from a set of photographs taken at one point in time to imagery of the same place shot months or years later, and other features may disappear completely as images are updated and replaced with newer ones. Inconsistencies in

\footnotetext{
3 37.337561, 141.019425 (September 2015).

4 37.5641889, 140.990176 (July 2015).

5 Real-time measurement of radioactivity in Fukushima Prefecture, provided by the prefecture itself, is available at fukushima-radioactivity.jp (Fukushima Prefecture n.d.).
} 
the dates at which adjacent photographs were taken cause waste piles to move, increase in size or disappear altogether as one moves through the map. These inconsistencies remind us that the visible landscape is a volatile product of the map producers' methodology (Perkins 2014).

It is not without irony that the 2013 Google Blog entry for the addition of Namie states "We want this Google Street View imagery to become a permanent record of what happened to Namie-machi in the earthquake, tsunami, and nuclear disaster" (Google and Baba 2013). Yet over the course of this study, for several months one of the frames above the text into which GSV imagery was embedded read "No Street View image available" because imagery for that location had been removed as part of an update and had not yet been replaced. GSV is not a complete or coherent representation of the current situation in Fukushima, with differing time-stamps in the data set, an invisible and indeterminate quality to the presence of radioactivity itself, and the continuous subdivision and reclassification of Fukushima's evacuated land as understanding of the precise nature of contamination improves (Ministry of Environment 2015). Great care and attention to wider contextual factors must be employed when using GSV as a means to understand the effects of radioactive contamination on the lived-in environment of post-disaster Fukushima. Equal circumspection is required when making claims as to the future recovery prospects of contaminated areas based on the GSV imagery. Assessing changes in contamination status over time is the next concern of this article.

\subsection{Tracking "Recovery" Over Time}

Specific to disasters, a key potential application of GSV and similar street-level photographic/video audits is the possibility of tracking recovery over time. Indeed, as outlined in Sect. 3 the possibility for GSV to chart recovery from tornadoes, hurricanes, and wildfires has been evaluated (Curtis et al. 2013), with Curtis et al. (2007) advocating the importance of tracking community return as a means of building resilience post-disaster. Given that the Japanese government is working towards the goal of decontamination in order to resettle at least some of those evacuated from their homes after the 2011 nuclear disaster (Ministry of Environment 2015), it is worth exploring whether GSV tracking over time could be extended to the decontamination and rehabilitation of radioactively-contaminated landscapes as well as natural disaster recovery in order to assess or at least keep abreast of progress.

Decontamination and resettlement progress is certainly in evidence in GSV for Fukushima. Workers powerwashing roads and cleaning drains, ${ }^{6}$ topsoil being removed and stored, ${ }^{7}$ even banners and signs declaring businesses are once again open and looking for customers ${ }^{8}$ are all visible. The recent addition to GSV of the ability to alternate between the most recent and earlier photographs may eventually make it possible to create a rudimentary longitudinal survey of decontamination, resettlement, and reconstruction work in affected areas of Fukushima, which would provide a model of how to chart recovery from other disasters elsewhere in the world. This would make it possible to show the efficacy of decontamination and resettlement work, as evidenced by the image sets from Odaka (in the south of Minami Soma) starting June 2013 and updated July 2015. These images display slow but nevertheless convincing initial decontamination work. ${ }^{9}$ Other image sites reveal places where progress over time is far less positive-in the town of Namie, for example, marked as a place where evacuee return will be difficult for a long time, up to five different image sets spanning a period of 30 months from March 2013 to September $2015^{10}$ reveal no change other than gradual and natural decay.

The time lapse function of GSV may thus help to understand not only "recovery," but also the potentially long term and/or irreversible nature of radioactive contamination. Most of the imagery from around FDNPP was added in early 2013, with a major update released in March 2016 showing new images taken in autumn 2015. Sporadic and piecemeal updates of some locations took place inbetween, but on the whole the imagery remained unchanged in the interim-a particular cause for concern in a fastchanging environment. For instance, the Kido ${ }^{11}$ and Tatsuta $^{12}$ railway stations appeared closed and boarded up in GSV until the March 2016 update, but in the "real world" had been open since spring 2014 in preparation of their surroundings for resettlement (The Japan Times 2014). The Joban Expressway was completed and opened to traffic in early 2015 , construction having been temporarily halted following the nuclear disaster. From some viewpoints in GSV it is shown as a fully-functioning road, ${ }^{13}$ but from others where images have not been updated construction still appears paused or incomplete. ${ }^{14}$ There is a need for researchers using GSV post-disaster to pay attention to the

\footnotetext{
6 37.5017406, 140.7641437 (September 2015).

7 37.3086021, 141.0202622 (September 2015).

8 37.2828591, 141.0038702 (July 2013).

${ }^{9}$ For example 37.564436, 140.9845872 (June 2013, July 2015); 37.5648163, 140.9949387 (June 2013, July 2015).

${ }^{10}$ For example, 37.4937898, 140.9903848 (March 2013-September 2015); 37.492244, 140.9935678 (March 2013-September 2015).

11 37.2578763, 141.0022788 (July 2013, September 2015).

12 37.2827612, 141.0023858 (July 2013, September 2015).

13 37.3855573, 140.9669836 (September 2015).

14 37.4865837, 140.9523226 (March 2013).
} 
possibility of recovery that may have taken place after the photos were taken, and to draw on wider contextual sources (for example, local news updates) to consider how the situation in a specific location may have changed over time since the GSV images were taken.

A series of snapshots may also not fully capture the complexities of remediating radioactive contamination over time. The case of Kawauchi Village, approximately fifteen $\mathrm{km}$ southwest of the nuclear plant, illustrates this point. The evacuation order for parts of Kawauchi was lifted fully in autumn 2014; it was previously classified as an area in preparation for the lifting order in which previous residents were permitted restricted stays (Sekiguchi 2014). In photographs with date stamps going back to June 2013, the village gives the impression of being settled and functioning, if a little sparsely populated-buildings appear recently repaired or in the process of being rebuilt, ${ }^{15}$ with well-maintained and freshly-laid surfaces such as asphalt and gravel roads. ${ }^{16}$ Kawauchi may thus score highly on the kinds of scales in other GSV-based studies to gauge environmental quality. For instance, it would score well on the characteristics of "aesthetic quality ${ }^{17}$ " and (lack of) "physical disorder, ${ }^{18}$ " and reasonably well on "sidewalk amenities $19 "$ and "human presence and social interactions $^{20 "}$ used by Rundle et al. (2011) to assess how environments may affect health and human behavior.

Using the metrics of Odgers et al. (2012) too, GSV images of Kawauchi would record low scores for the "disorder" characteristics (defined by Odgers et al. as abandoned or burned out cars and vandalized/faded signs among others), "decay" characteristics (sidewalk condition, deteriorated residential units, deteriorated gardens), and the "danger" signs characteristic of "unsafe place to live" unless viewers brought with them prior knowledge of radioactivity. However, it is vital to remember this is a view from the road, from a vehicle passing through the landscape and predominately capturing other vehicles passing through the landscape- not the view of those who live in irradiated landscapes and deal with myriad indeterminacies on a daily basis (Morris-Suzuki 2014). Echoing Rousselet et al. (2013) on GSV being more suited for nearroad observation and Kelly et al. (2013) on GSV's focus on urban environments, it is hard to gauge the need to decontaminate across the whole ecosystem as opposed to the areas immediately around people's homes. This view from the road may also flatten some of the societal

\footnotetext{
$1537.342998,140.8047347$ (October 2015).

$1637.3452625,140.8040362$ (September 2015).

17 For example 37.328327, 140.8335064 (June 2014).

18 For example 37.3365852, 140.8100234 (September 2015).

19 For example 37.3443051, 140.8045435 (October 2015).

${ }^{20}$ For example 37.3378986, 140.8095051 (September 2015).
}

complexities around "return"-delays in the lifting of the evacuation order due to residents' skepticism over lingering radioactivity and subsequent demands for further decontamination, the low number of people (especially young people) willing to risk return, and the associated collapse of community life (Endo 2012). A paucity of social life is often enhanced by the difficulty of daily life due to a lack of amenities and infrastructure such as supermarkets (Asanuma-Brice 2014). A two-dimensional photomontage can show physical changes in the environment, but may struggle to encompass the social and ecosystem complexities of post-nuclear disaster recovery.

It may thus be the case that whilst GSV has potential to offer a general, high-level overview of recovery over time post-disaster, the frequency of updates may struggle to keep abreast of subsequent developments in the landscape. The "view from the road" may also not grasp the environmental and social complexities of recovery over time. As the following section argues, tempering the view from the camera with wider understanding of the sociopolitical context of disaster recovery is crucial if GSV is to be a valuable research tool.

\subsection{Sociopolitical Contexts of Disaster and Recovery}

As outlined in Sect. 3, auditing the built environment through GSV has been positively evaluated for being objective (van Wolleghem et al. 2014), reliable (Kelly et al. 2013), and allowing viewers to understand the landscape "as if in reality" (Badland et al. 2010, p. 1008). When it comes to disasters, the less immediately visible sociopolitical setting cannot be ignored; Smith (2006) argues that "there is no such thing as a natural disaster. In every phase and aspect of a disaster-causes, vulnerability, preparedness, results and response, and reconstruction-the contours of disaster and the difference between who lives and who dies is to a greater or lesser extent a social calculus." With Blowers (1999) also arguing it is impossible to assess landscapes of risk without understanding the imbalances and injustices contained within them, it follows that if GSV is to be a helpful tool for evaluating the nature of and recovery from the societal effects of disasters like Fukushima, the viewer ought to engage not only with what is happening, but also to pay attention to questions of who decides what happens in particular locations and where imbalances may exist in making these decisions. It is arguably not the aim of GSV to make visible these injustices and inequalities, but it is nevertheless crucial to consider two things: (1) whether the view is as "objective" as we may think it is; and (2) how much of the social dynamics of a disaster we can glean from GSV itself versus where the onus lies with the researcher to supplement the view "on screen" with additional understanding. 
As Power et al. (2013) point out, the question of who has control of technology, and what their views and perceptions are, can influence what the "objective" GSV camera includes and excludes. This is particularly true for radioactive contamination, where access to affected areas (and the technology to make radiation visible) may be privileged (Davies 2013). This means that the way in which a nuclear landscape like that in Fukushima is represented will be a product of those with such privileges. For example, Fukushima's nuclear power plants themselves are virtually invisible in GSV. Much like Ireland's Moyross housing estate in Power et al.'s (2013) study, Fukushima Dai' ichi is viewable only in brief glimpses from a "safe" distance. Save for occasional sightings of cranes rising over tree tops, ${ }^{21}$ water tanks appearing in the gaps in the perimeter, ${ }^{22}$ and pylons crossing fields and disappearing into the forest surrounding the plant, ${ }^{23}$ FDNPP is largely erased from GSV. Navigate close to the plant and the ability to move any closer will cease, the publicly-accessible and navigable data set comes to an end while the photograph shows roads leading to the plant stretching off into the distance. On occasions on the roads near to FDNPP-as was encountered during the research for this study-a click forwards will cause the whole screen to go black, the words "This image is not currently available" appearing in place of the usual photography with no further explanation as to why the particular photo is unavailable. There may be pragmatic safety and security reasons for limiting what is publicly viewable at any point in time, or where the photographing vehicles were not logistically able to access in the first instance. Other nuclear power plants on GSV, for instance Onagawa in Miyagi Prefecture ${ }^{24}$ and Sendai in Kagoshima Prefecture, ${ }^{25}$ remain equally off-limits to the viewer. Nonetheless, this illustrates very well the privilege of not only access to but also representation of the nuclear landscape-by granting Google access to areas of high radioactivity but also limiting access to nuclear plants themselves, governors and plant operators can influence what is seen and what remains invisible in GSV to an extent that "ordinary" citizens perhaps cannot so easily do.

If the awareness of wider sociopolitical factors exhibited by Smith (2006) and Blowers (1999) is a key component of understanding disasters or landscapes of risk, then reflection is required on the extent to which GSV allows us to understand these social relations. This is important if only to get a sense of how much extra work researchers may need to do (for example, through surveys of news articles,

\footnotetext{
$2137.4280974,141.0220704$ (September 2015).

$2237.4112675,141.0306823$ (June 2013).

23 37.4208554, 141.0147266 (June 2013).

24 38.4082724, 141.5015807 (October 2011).

$2531.8287875,130.1922435$ (January 2012).
}

meta-analyses of other social science studies, or their own empirical quantitative or qualitative research) in order to come to a more robust understanding of the human dimensions of a disaster. The visibility of waste storage in the Fukushima GSV landscape illustrates well this need to supplement GSV viewing with wider awareness of the situation before making an assessment as to the "recovery" of the area. The initial stages of large-scale waste repositories are present in GSV imagery, particularly in the coastal areas much closer to FDNPP. ${ }^{26}$ Periodic updates of images may allow one to track the emergence of these repositories, but missing from the images are the politics of siting these waste storage facilities and the question of what becomes of places that take up the waste for others (Gill 2013). For instance, from the map one cannot know of the government plans to build a large temporary repository on the border of Futaba and Okuma towns (Ministry of Environment 2015), let alone the opposition from some residents to the plans and perceived pressure from central government to accept the repositories (The Japan Times 2015). In other words, missing from the GSV "map" is an indication of contestations over what is to become of places after the camera departs (Kirsch 1997). If one is to chart the progress of irradiated landscapes over time through GSV, it would thus seem important to supplement the visual imagery of recovery (or otherwise) with additional knowledge about whether citizens themselves agree with the trajectory the landscape is following.

There is likewise little room to engage with the multiple ways in which citizens themselves may understand the landscape and their relationship to energy infrastructure (Parkhill et al. 2014). Blowers (1999) believes awareness of the relationship between nuclear energy infrastructure and surrounding communities is key to full and proper understanding of nuclear landscapes - and in the case of Fukushima, this may also be intrinsically bound up with perceptions of who is responsible for causing, and who is responsible for redressing, the effects of a nuclear accident (Sugai 2012). The imbalance in the Fukushima relationship is illustrated by the Nakamura and Kikuchi (2011) analysis of the historical dependency of small towns such as Futaba on the nuclear industry for employment, infrastructure, and economic prosperity. Yet there is little trace of the fact that part of Futaba is now under pressure to house a repository for radioactive waste from elsewhere in Fukushima (Fukushima Minpo 2015). If one looks hard enough and/or in the right places, minute traces of contestation over the role of nuclear power in the landscape can be detected on camera. An incomplete block of flats in $\mathrm{Futaba}^{27}$ bears

\footnotetext{
${ }^{26}$ For example 37.3376326, 141.0240458 (September 2015); 37.357154, 141.0295003 (August 2015).

27 37.4534079, 141.0090554 (July 2013, September 2015).
} 
graffiti reading genpatsu totomoni aruinda kekka...(gone with nuclear power) in the July 2013 image, and an antinuclear power poster in the September 2015 update. Signage in Hirono encourages laborers at the plant to ensure they hold their employers to the maintenance of good working conditions ${ }^{28}$; and one may find the Kibounobokujo (Ranch of Hope), ${ }^{29}$ which refuses to cull cattle even though they are unsellable (Kibounobokujyo-Fukushima 2015).

Moreover, the nature of GSV limits how much of the broader social and historical context can readily be known. For instance, Rieu (2013) maintains that what really happened at Fukushima was the result of a power structure that led to the plant being sited in a vulnerable setting. In other words, the process leading to the Fukushima accident was initiated not by a large-scale earthquake, but by a power structure of close relationships between governors, industry, and media stretching over decades. This power structure, Rieu argues, engendered lax standards, ineffective regulation, and questionable opportunities for community consent during the advancement of nuclear sites. As such, when the disaster struck and these more negative aspects of the way nuclear power was governed came to the surface, the result was a complete collapse of citizen trust in the government and TEPCO. This same lack of trust is now a major barrier in getting citizen support for post-disaster rehabilitation initiatives (Sato 2014). Attention to social and historical processes can thus explain not only how a disaster happened, but also why certain recovery strategies may be challenging or undesirable. Comprehensive understanding of what really happens during and after a disaster like Fukushima perhaps requires awareness of the "unseen" social dynamics and historical context as well as the immediate physical effects that GSV allows scholars to access remotely.

A clear and undeniable aspect of understanding the Fukushima disaster is the huge impact on the lives of residents living close to the nuclear plant. Yet these people and their stories are largely missing from the landscape. These concerns do not mean GSV cannot be used in disaster situations. Rather, what the author wishes to highlight is that when using GSV as a means of assessing postdisaster effects and recovery, there is a need to exercise caution when "classifying" landscapes based on imagery. These digital representations may not be as objective as we are led to believe. Researchers must recognize where further contextual understanding is required (whether through empirical research or secondary sources) to explain what is visible on the map or to make visible social processes that are not captured by the cameras.

\footnotetext{
$2837.1982261,140.959924$ (July 2013).

$2937.5294365,140.9373787$ (July 2015).
}

\section{Discussion}

The value GSV provides needs to be balanced by a clear grasp of technology's limitations in generating a full understanding of the societal effects of disaster and disaster recovery. Specific to Fukushima, the photographic montage presented gives-close to the plant at least-a clear indication of the magnitude of the problems involved in managing evacuated land. It also gives a sense of the ongoing nature of the Fukushima crisis by allowing scholars to view the situation in areas where human access is prohibited or restricted, and identifies the areas where return is not yet possible. In places where imagery has been refreshed over time, rudimentary "tracking" of recovery and rehabilitation is possible in terms of assessing decontamination, resettlement, and the rehabilitation of businesses.

Equally, though, what is missing if not actively discouraged for GSV in Fukushima is actual information on environmental radioactivity, and a sense of how this is interpreted and/or contested by different actors. There is virtually nothing to give the viewer a direct sense of the relative levels of contamination in different places, and in the absence of this basic information (and of course the invisibility of radiation itself) the viewer has to rely on visual proxies for high radioactivity. These proxies generally indicate a lack of human activity, which rightly or wrongly are taken to mean an area is too dangerous for humans to inhabit. Such proxies may include the extent to which the built environment is overgrown with weeds, the lack of repair to damage caused during the earthquake and tsunami, or even the presence of signage and gates erected post-2011 marking areas out as being off-limits due to high radioactivity. Instability in the dates at which images are taken has the potential to pose problems for auditing recovery, as does the infrequent updating of GSV that may leave off more recent developments. The view presented is also one from the road rather than from within the landscapes, where there may be ecological and societal complexities around assessing adequate rehabilitation and resettlement.

What are the wider implications of this study into the use of GSV for disasters and disaster recovery? The invisibility of radiation and its potential in sufficient doses to harm anything in contact with it makes it difficult for researchers to assess radioactive environments in person. The physical impacts of other disasters such as earthquakes, tornadoes, and floods are generally more visible and do not in themselves pose further risks to researchers in the way radiation does. The idea that GSV allows researchers access to an otherwise dangerous environment may have limited utility beyond disasters involving 
radiation or other environmental contamination. But this does reinforce extant thinking that there is fundamental value in a tool that allows scholars to view "risky" environments of the kind that may exist post-disaster without access challenges or exposure to additional dangers. This study also suggests that rudimentary auditing of the environment and assessment of recovery may be possible for "invisible" hazards like radiation, pollution and heat, as well as the more visible damage caused by extreme weather or seismic activity. Some of the concerns raised in extant studies about spatiotemporal instability of images and the infrequent/nontransparent updating of images were also borne out for Fukushima.

At the same time, this study and reference to broader social science literature raises additional concerns as to the value of GSV in post-disaster situations. It is here that the links to researching natural disasters with more visible impacts and fewer access issues become clearer. As the article has argued, scholars using GSV need to reflect: (1) within GSV on how "objective" the map may be, in particular what is included, what is excluded and why; and (2) beyond GSV to understand how disaster and disaster recovery are perceived across different groups, and thus what the wider forces are shaping what is visible in the GSV landscape. Above all else, proper assessment of disaster landscapes in GSV requires both visual understanding of the situation, and also wider contextual information on multiple interpretations of this "science" and its relationship to competing narratives of place-something a volatile and two-dimensional digital map on its own can only address in limited fashion.

Acknowledgments The material and ideas in this article are based on preliminary reading undertaken as part of a Japan Foundation Fellowship; however all responsibility for the ideas and opinions expressed within lies with the author alone.

Open Access This article is distributed under the terms of the Creative Commons Attribution 4.0 International License (http://crea tivecommons.org/licenses/by/4.0/), which permits unrestricted use, distribution, and reproduction in any medium, provided you give appropriate credit to the original author(s) and the source, provide a link to the Creative Commons license, and indicate if changes were made.

\section{References}

Asahi Shimbun. 2014. Google Maps shows state of disaster recovery along Tohoku coastline, 20 October 2014. http://newsonjapan. com/html/newsdesk/article/109939.php. Accessed 11 Nov 2015.

Asanuma-Brice, C. 2014. Beyond reality-or-An illusory ideal: Pronuclear Japan's management of migratory flows in a nuclear catastrophe. The Asia-Pacific Journal 12(47): 1.

Badland, H., S. Opit, K. Witten, R. Kearns, and S. Mavoa. 2010. Can virtual streetscape audits reliably replace physical streetscape audits? Journal of Urban Health: Bulletin of the New York Academy of Medicine 87(6): 1007-1016.

Bahre, C.J. 1991. A legacy of change: Historic human impact on vegetation in the Arizona borderland. Tucson, AZ: Arizona Press.

Blowers, A. 1999. Nuclear waste and landscapes of risk. Landscape Research 24(3): 241-264.

Curtis, A., J.W. Mills, B. Kennedy, S. Fotheringham, and T. McCarthy. 2007. Understanding the geography of post-traumatic stress: An academic justification for using a spatial video acquisition system in the response to Hurricane Katrina. Journal of Contingencies \& Crisis Management 15(4): 208-219.

Curtis, A., and J. Mills. 2012. Spatial video data collection in a postdisaster landscape: The Tuscaloosa Tornado of April 27th 2011. Applied Geography 32(2): 393-400.

Curtis J.W., A. Curtis, J. Mapes, A.B. Szell, and A. Cinderich. 2013. Using Google Street View for systematic observation of the built environment: Analysis of spatio-temporal instability of imagery dates. International Journal of Health Geographics 12: 53. doi:10.1186/1476-072X-12-53.

Curtis, A., J.W. Curtis, E. Shook, S. Smith, E. Jefferis, L. Porter, L. Schuch, C. Felix, and P.R. Kerndt. 2015. Spatial video geonarratives and health: Case studies in post-disaster recovery, crime, mosquito control and tuberculosis in the homeless. International Journal of Health Geographics 14: 22. doi:10.1186/s12942-0150014-8.

Davies, T. 2013. A visual geography of Chernobyl: Double exposure. International Labour and Working-Class History 84: 116-139.

Endo, Y. 2012. Situation in Kawauchi-mura after the earthquake and effort toward recovery. https://www.oecd-nea.org/rp/meetings/ ISTC-STCU/docs/5-feb-fukushima/15\%20Endo(Kawauchi_Vil lage)_English.pdf. Accessed 11 Nov 2015.

Exeter D.J., S. Rodgers, and C.E. Sabel. 2014. "Whose data is it anyway?" The implications of pitting small area-level health and social data online. Health Policy 114(1): 88-96.

Fukushima Minpo. 2012. Futaba town dissatisfied with national radiation dose standards. Fukushima Minpo News, 24 August 2012. http://www.fukushimaminponews.com/news.html?id=79. Accessed 11 Nov 2015.

Fukushima Minpo. 2015. Futaba town to accept construction of temporary nuke waste storage facility. Fukushima Minpo News, 14 January 2015. http://www.fukushimaminponews.com/news. html?id=456. Accessed 11 Nov 2015.

Fukushima Prefecture. n.d. Fukushima prefecture radioactivity measurement map. http://fukushima-radioactivity.jp/. Accessed 11 Nov 2015.

Gill, T. 2013. This spoiled soil: Place, people and community in an irradiated village in Fukushima prefecture. In Japan copes with calamity: Ethnographies of the earthquake, tsunami and nuclear disasters of March 2011, ed. T. Gill, B. Steger, and D. Slater, 201-234. Oxford: Peter Lang.

Google. n.d. About the memories for the future project in Japan, Google memories for the future project. http://www.miraikioku. com/streetview/en/about. Accessed 11 Nov 2015.

Google. 2014. Google official blog, 23 April 2014: Go back in time with Street View. https://googleblog.blogspot.co.uk/2014/04/goback-in-time-with-street-view.html. Accessed 11 Nov 2015.

Google, and T. Baba. 2013. Google official blog, 27 March 2013: Imagery on Google Maps of Fukushima exclusion zone town Namie-machi. http://googleblog.blogspot.co.uk/2013/03/ima gery-on-google-maps-of-fukushima.html. Accessed 11 Nov 2015.

Gregson, N. 2012. Projected futures: The political matter of UK higher activity radioactive waste. Environment and Planning $A$ 44(8): 2006-2022. 
Hastings, J.R., and R.M. Turner. 1965. The changing mile: An ecological study of vegetation change with time in the lower mile of an arid and semiarid region of Arizona. Tucson, AZ: Arizona Press.

Kasperson, R.E., N. Jhaveri, and J.X. Kasperson. 2001. Stigma and the social amplification of risk: Towards a framework of analysis. In Risk, media and stigma, ed. J. Flynn, P. Slovic, and H. Kunreuther, 9-27. London: Earthscan.

Kawai, K. 2011. Google official blog, 12 December 2011: Experience the tsunami-affected areas of Japan through Street View. http:// googleblog.blogspot.co.uk/2011/12/experience-tsunami-affectedareas-of.html. Accessed 11 Nov 2015.

Kawai, K. 2012. Google official blog, 6 December 2012: Explore digital archives of buildings in Japan affected by the 2011 tsunami. http://googleblog.blogspot.co.uk/2012/12/explore-digi tal-archives-of-buildings.html. Accessed 11 Nov 2015.

Kelly, C.M., J.S. Wilson, E.A. Baker, D.K. Miller, and M. Schootman. 2013. Using Google Street View to audit the built environment: Inter-rater reliability results. Annals of Behavioural Medicine 45(18): 108-112.

Kibounobokujyo-Fukushima. 2015. Ranch of hope-Fukushima (Kibounobokujyo-Fukushima). http://blog.goo.ne.jp/kibounobokujyou. Accessed 11 Nov 2015 (in Japanese).

Kirsch, S. 1997. Watching the bombs go off: Photography, nuclear landscapes, and spectator democracy. Antipode 29(3): 227-255.

Less, E.L., P. McKee, T. Toomey, T. Nelson, D. Erickson, S. Xiong, and R. Jones-Webb. 2015. Matching study areas using Google Street View: A new application for an emerging technology. Evaluation and Program Planning 53: 72-79.

McNeill, D., and M. Quintana. 2013. Mission impossible: What future Fukushima? The Asia-Pacific Journal 11(39): 1.

Ministry of the Environment. 2015. Progress on offsite cleanup efforts in Japan. http://josen.env.go.jp/en/pdf/progressseet_progress_ on_cleanup_efforts.pdf?141022.html. Accessed 11 Nov 2015.

Morris-Suzuki, T. 2014. Touching the grass: Science, uncertainty and everyday life from Chernobyl to Fukushima. Science, Technology and Society 19: 331-362.

Nakamura, A., and M. Kikuchi. 2011. What we know, and what we have not yet learned: Triple disasters and the Fukushima nuclear fiasco in Japan. Public Administration Review 71(6): 893-899.

National Geophysical Data Center. 2015. March 11, 2011 Japan Earthquake and Tsunami. National Geophysical Data Center. ftp://ftp.ngdc.noaa.gov/hazards/publications/2011_0311.pdf. Accessed 6 Jun 2016

Odgers, C.L., A. Caspi, C.J. Bates, R.J. Sampson, and T.E. Moffitt. 2012. Systematic social observation of children's neighbourhoods using Google Street View: A reliable and cost-effective method. Journal of Child Psychology and Psychiatry 53(10): 1009-1017.

Parkhill, K., C. Butler, and N. Pidgeon. 2014. Landscapes of threat? Discourses of stigma around large energy developments. Landscape Research 39(5): 566-582.

Perkins, C. 2014. Plotting practices and politics: (Im)mutable narratives in OpenStreetMap. Transactions of the Institute of British Geographers 39: 304-317.

Pezullo, P., and S.P. Depoe. 2010. Everyday life and death in a nuclear world: Stories from Fernald. In Public modalities: Rhetoric, culture, media, and the shape of public life, ed. D.C. Brouwer, and R. Asen, 85-108. Tuscaloosa: University of Alabama Press.

Pink, S. 2012. Visual ethnography and the internet: Visuality, virtuality and the spatial turn. In Advances in visual methodology, ed. S. Pink, 113-130. London: Sage.

Power, M.J., P. Neville, E. Devereux, A. Haynes, and C. Barnes. 2013. 'Why bother seeing the world for real?': Google Street
View and the representation of a stigmatised neighbourhood. New Media \& Society 15(7): 1022-1040.

Reconstruction Agency. 2015. The status in Fukushima. https://www. reconstruction.go.jp/english/topics/2013/03/the-status-in-fukush ima.html. Accessed 3 Feb 2015.

Rieu, A.-M. 2013. Thinking after Fukushima Epistemic shift in social sciences. Asia-Europe Journal 11(1): 65-78.

Rose, G. 2001. An introduction to the interpretation of visual materials. London: Sage.

Rousselet, J., C.-E. Imbert, A. Dekri, J. Garcia, F. Goussard, B. Vincent, O. Denux, C. Robinet,, F. Dorkeld, A. Roques, and J-P. Rossi. 2013. Assessing species distribution using Google Street View: A pilot study with the pine processionary moth. PLOS One 8(10): e74918. doi:10.1371/journal.pone.0074918.

Rundle, A., M. Bader, C. Richards, K. Neckerman, and J. Teitler. 2011. Using Google Street View to audit neighbourhood environments. American Journal of Preventative Medicine 40(1): 94-100.

Saito, K., I. Tanihata, M. Fujiwara, T. Saito, S. Shimoura, T. Otsuka, Y. Onda, M. Hoshi, Y. Ikeuchi, F. Takahashi, N. Kinouchi, J. Saegusa, A. Seki, H. Takemiya, and T. Shibata. 2015. Detalied deposition density maps constructed by large-scale soil sampling for gamma-ray emitting radioactive nuclides from the Fukushima Da'ichi nuclear power plant accident. Journal of Environmental Radioactivity 139: 308-319.

Sato, A. 2014. Issues related to nuclear accident evacuees: What has been observed while attending town hall meetings. In Proceedings of the pre-congress conference on sustainability and environmental sociology, 12-13 July 2014, Yokohama, Tokyo: Hosei University, 21-28.

Sekiguchi, T. 2014. Fukushima refugees wary of returning home. Wall Street Journal, 23 October 2014. http://www.wsj.com/ articles/fukushima-refugees-wary-of-returning-home-1414099802. Accessed 3 Feb 2015.

Smith, N. 2006. There's no such thing as a natural disaster. Understanding Katrina: Perspectives from the social sciences. New York: Social Science Research Council. http://understan dingkatrina.ssrc.org/Smith/. Accessed 15 Oct 2015.

Sugai, M. 2012. How do we make TEPCO and the government take responsibility? Human 17: 8-14.

The Japan Times. 2014. National trains resume runs in hot zone, 01 June 2014. http://www.japantimes.co.jp/news/2014/06/01/ national/trains-resume-runs-hot-zone/\#.VhUzfsltWZR. Accessed 11 Nov 2015.

The Japan Times. 2015. Town near wrecked Fukushima No. 1 plant to host 30-year radioactive dump, 14 January 2015. http://www. japantimes.co.jp/news/2015/01/14/national/futaba-accept-radio active-soil-storage-facilities/\#.VOXO-8m0KZT. Accessed 11 Nov 2015.

Vandeviver, C. 2014. Applying Google Maps and Google Street View in criminological research. Crime Science: An Interdisciplinary Journal 3: 13. doi:10.1186/s40163-014-0013-2.

van Wolleghem, G., D. van Dyck, F. Ducheyne, I. de Bourdeaudhuij, and G. Cardon. 2014. Assessing the environmental characteristics of cycling routes to school: A study on the reliability and validity of a Google Street View-based audit. International Journal of Health Geographics 13: 19. doi:10.1186/1476-072X13-19.

Wakeford, R. 2011. And now, Fukushima. Journal of Radiological Protection 31(2): 167-176.

Zook, M.A., and M. Graham. 2007. Mapping DigiPlace: Geocoded internet data and the representation of place. Environment and Planning B: Planning and Design 34: 466-482. 